Bio-grafía. Escritos sobre la Biología y su Enseñanza. ISSN 2027-1034

Número Extraordinario. p.p. 33-39

Memorias del Primer encuentro ambiental Universidad, ambiente y sustentabilidad: experiencias y prácticas.

\title{
CONTAMINACIÓN AMBIENTAL EN EL TERRITORIO DE USME A PARTIR DE PRÁCTICAS SUSTENTABLES DESDE EL ENFOQUE ANCESTRAL
}

\section{Melo Romero Andrea Del Pilar ${ }^{1}$}

\section{Resumen}

En este artículo se pretende analizar la manera en que las prácticas sustentables desde el enfoque ancestral, permiten una mejor comprensión de la contaminación ambiental del territorio de Usme, contribuyendo a la mitigación de los problemas ambientales a partir de la formación de ciudadanos responsables.

La investigación se fundamenta en tres aspectos, el primero de ellos la educación ambiental como eje primordial ya que partimos de un contexto de educación formal en el sector oficial del Colegio Miguel De Cervantes Saavedra. El segundo aspecto refiere a las tipologías de sustentabilidad, propuestas por Gudynas (2009), quien sostiene que el medio ambiente y sus recursos no pueden reducirse a un capital natural, debe asegurarse su mantenimiento más allá de su utilidad. El tercer aspecto es el pensamiento ancestral que será la base de las prácticas sustentables, como la resignificación del territorio, vivir en armonía con la naturaleza, valorar los saberes ancestrales que han pasado por una tradición oral, entre otros... Hasta el momento en la investigación se han encontrado en las concepciones de los estudiantes, relaciones con las corrientes naturalista y conservacionista propuestas por Sauve (2004), un segundo hallazgo de la indagación inicial sostiene que la sustentabilidad se manifiesta por las prácticas agrícolas, el equilibrio entre la producción, el medio ambiente y la calidad de vida de los miembros de la comunidad.

${ }^{1}$ 1. Estudiante de Maestría en Docencia de la Química Universidad Pedagógica Nacional. Lic. En Biología. Docente de la secretaria de educación distrital. Grupo de investigación. "Educación en Ciencias, Ambiente y Diversidad. anddpmelo@gmail.com 
Bio-grafía. Escritos sobre la Biología y su Enseñanza. ISSN 2027-1034

Número Extraordinario. p.p. 33-39

Memorias del Primer encuentro ambiental Universidad, ambiente y sustentabilidad: experiencias y prácticas.

Palabras Clave: Educación ambiental, sustentabilidad, pensamiento ancestral.

\section{Abstract}

This article aims to analyze how sustainable from the ancestral approach, practices allow a better understanding of environmental pollution Usme territory, contributing to the mitigation of environmental problems from the formation of responsible citizens.

The research is based on three aspects, the first of which environmental education as a linchpin because we start from a context of formal education in the formal sector of Miguel De Cervantes Saavedra College. The second aspect refers to typologies of sustainability, proposed by Gudynas (2009), who argues that the environment and its resources can not be reduced to natural capital, you must ensure its maintenance beyond its usefulness. The third aspect is the ancestral thought that is the basis of sustainable practices, such as the redefinition of the territory, live in harmony with nature, value ancestral wisdom that have gone through an oral tradition, among others ...

So far in the investigation were found in the conceptions of students, relations with the naturalist currents and conservationist proposed by Sauve (2004), a second finding of the initial inquiry argues that sustainability is manifested by agricultural practices, balance between production, the environment and quality of life of community members.

Keywords: Environmental education, sustainability, ancestral thought.

\section{OBJETIVO GENERAL}

Promover la formación de ciudadanos ambientalmente responsables, a partir del estudio de la contaminación en el territorio de Usme, tomando como referencia la sustentabilidad. 
Bio-grafía. Escritos sobre la Biología y su Enseñanza. ISSN 2027-1034

Número Extraordinario. p.p. 33-39

Memorias del Primer encuentro ambiental Universidad, ambiente y sustentabilidad: experiencias y prácticas.

\section{OBJETIVOS ESPECÍFICOS}

* Reconocer las concepciones que circulan en los estudiantes de ciclo II del Colegio MIGUEL DE CERVANTES SAAVEDRA sobre ambiente y territorio, mediante entrevistas y análisis pictográficos, con el propósito de analizar su interacción con la sustentabilidad.

* Incentivar el conocimiento y la investigación de problemas ambientales por parte de los estudiantes del colegio MIGUEL DE CERVANTES SAAVERDRA, para la comprensión de aspectos biológicos, químicos, sociales y culturales por medio de la cartografía social y el Mapeo Analítico Reflexivo

* Resignificar el pensamiento ancestral y la ciudadanía ambiental responsable a través de prácticas sustentables, por medio del aprendizaje basado en proyectos.

\section{FUNDAMENTACIÓN TEORICA}

El concepto de sustentabilidad nace, cuando la humanidad comprende que la naturaleza es la base de todos los procesos de producción de la sociedad. "El principio de sustentabilidad emerge en el contexto de la globalización como la marca de un límite y el signo que reorienta el proceso civilizatorio de la humanidad" (Leff, 2002, p17).

El concepto de desarrollo sustentable para Foladori (2002) contiene tres dimensiones: La ecológica, la económica y la social. La sustentabilidad ecológica encierra el equilibrio, conservación y mantenimiento de los ecosistemas incluyendo la biodiversidad, factores abióticos como los recursos naturales y el clima. Para poder medir la sustentabilidad ecológica se basa en un concepto de integridad mientras menos intervención entrópica tengan los ecosistemas mayor sustentabilidad ecológica presentan. La sustentabilidad económica entendida como el balance entre el crecimiento económico y la eficiencia productiva trataría de sustituir recursos no renovables por aquellos renovables disminuyendo los problemas ambientales.

Finalmente, la sustentabilidad social es entendida como el equilibrio de las relaciones de producción con el medio ambiente externo que mejoran la 
Bio-grafía. Escritos sobre la Biología y su Enseñanza. ISSN 2027-1034

Número Extraordinario. p.p. 33-39

Memorias del Primer encuentro ambiental Universidad, ambiente y sustentabilidad: experiencias y prácticas.

calidad de vida de las comunidades, la apropiación de los recursos sin tocar las relaciones de producción, encierra relaciones de equidad, pobreza, demografía con el medio ambiente y por esta razón la necesidad de integrar proyectos de participación social que generen transformaciones radicales en las comunidades.

Se puede clasificar la sustentabilidad por medio de tres corrientes propuestas por Gudynas (2009). La primera una sustentabilidad débil que advierte la existencia de una necesidad por cambiar los procesos productivos, estos permiten la mitigación de los problemas ambientales y el crecimiento económico, promoviéndose el concepto de capital natural, dándole un valor económico a los recursos naturales, con un carácter utilitarista y antropocéntrico. La segunda corriente, refiere a una sustentabilidad fuerte, promueve que la naturaleza no se puede reducir a una valoración económica, pero hace hincapié por la conservación y protección con un carácter antropocéntrico. La tercera corriente es la sustentabilidad súper fuerte, cuya valoración de la naturaleza debe estar sustentada desde varios aspectos como lo cultural, ecológico, social, religioso o estético, pero debe ser independiente del factor económico que puede brindar sus recursos.

\section{METODOLOGÍA}

Esta investigación se está realizando en el Colegio Miguel de Cervantes Saavedra I.E.D, ubicado en el Barrio Santa Librada, en la localidad 5a Usme, de Bogotá Colombia. Son 27 estudiantes de la jornada tarde del grado quinto, que pertenecen a los estratos uno y dos.

Se hace uso diseño cualitativo microetnografico, para su realización se utilizan instrumentos como; entrevistas, observaciones en los espacios escolares, recolección y análisis de fotos, textos, entre otros, la construcción de los relatos microetnográficos permiten describir las experiencias personales, las instituciones y las prácticas profesionales (Díaz de Rada, 2014).

\section{Fases de la metodología}

Para la investigación se plantean 3 fases. En la primera de ellas se aborda el diagnóstico de las concepciones de los estudiantes sobre el ambiente y su 
Número Extraordinario. p.p. 33-39

Memorias del Primer encuentro ambiental Universidad, ambiente y sustentabilidad: experiencias y prácticas.

territorio por medio de entrevistas y análisis pictográficos. En la segunda fase se realizará la inmersión en la comprensión de algunos problemas ambientales de la localidad de Usme, por medio de la cartografía social y el mapeo analítico reflexivo. Posteriormente, por medio de la estrategia didáctica basada en proyectos, se orientará a los estudiantes frente a las prácticas sustentables y el pensamiento ancestral, para que ellos puedan formular preguntas problema a partir de su contexto inmediato. En la tercera fase se triangulará la información compilada en el diagnóstico, la orientación de las prácticas sustentables y el pensamiento ancestral con los resultados del desarrollo de los proyectos.

\section{RESULTADOS Y CONCLUSIONES PREELIMINARES}

Cuando a los estudiantes se les pide representar lo que entienden por ambiente recrean dibujos como los de las fotografías: montañas, nubes, sol, ríos, algunos seres vivos como mariposas, peces, aves, gatos, perros, conejos, árboles, cactus, flores, seres humanos en contacto constante con la naturaleza, se dibujan ellos mismos e incluyen imágenes con frases alusivas al cuidado y protección del medio ambiente.

Se puede identificar a primera vista que los estudiantes conciben el ambiente como la naturaleza, saben que ella requiere de cuidado y protección, su ideal en cuanto a lo que quisieran ver en su medio ambiente, dibujan a los seres humanos realizando acciones de protección, disposición adecuada de residuos sólidos, cultivando, cosechando, y en procesos de reforestación. Las concepciones de los estudiantes se relacionan con la corriente naturalista propuesta por Sauvé, (2004) en donde los estudiantes identifican las formas de vida, lo no viviente, la biodiversidad, la relación del hombre con la naturaleza, como una parte integrante de ella, la necesidad de la resolución de problemas ambientales de su comunidad y el deseo innato de aprender de la naturaleza a partir del contacto con ella de una forma experiencial.

En cuanto al reconocimiento de su localidad, tiene presente sus barrios, ciertos lugares como: estaciones, bibliotecas, el territorio representado por medio de los símbolos patrios, las casas, parques, colegios y el comercio en general. Alcanzan a describir la amabilidad de sus pobladores, pero hay desconocimiento de la historia cultural de Usme, mínimos relatos y dibujos que puedan dar cuenta de lo cultural, de lo social, de la identificación de ese 
Bio-grafía. Escritos sobre la Biología y su Enseñanza. ISSN 2027-1034

Número Extraordinario. p.p. 33-39

Memorias del Primer encuentro ambiental Universidad, ambiente y sustentabilidad: experiencias y prácticas.

patrimonio natural propio de la corriente del desarrollo sustentable súper fuerte desarrollada por Gudynas (2009).

Se les pidió a los estudiantes que crearan un súper héroe que pudiera combatir las problemáticas ambientales institucionales y que tuviera relación con las cosmovisiones de su territorio. Como se evidencia en las fotografías de los dibujos, se puede interpretar que en la personificación de los estudiantes sus súper héroes tienen poderes para la protección de los recursos naturales, optimizar el manejo adecuado de los residuos sólidos, cuidado del medio ambiente por medio de la siembra de los árboles y finalmente enseñar a los niños la responsabilidad que tienen con su entorno.

De esta manera se manifiesta que entre las principales problemáticas ambientales institucionales están: el manejo inadecuado de los residuos sólidos, el maltrato a los seres vivos de su entorno y el desperdicio de los servicios públicos agua y energía eléctrica. Se evidencia una necesidad de recurrir a estrategias tendientes a la conservación de los recursos naturales y solución de problemas como las enunciadas respectivamente en la corriente conservacionista y resolutiva de Sauvé (2004).

En una minoría de los estudiantes se observó el reconocimiento cultural muisca al dibujar la princesa Usminia tal como se encuentra en el monumento de la avenida Boyacá con Caracas de la localidad de Usme. Representaron en sus dibujos los adultos mayores con su conocimiento ancestral y con súper poderes para la conservación del agua.

Se espera que a partir de la implementación de las prácticas sustentables se promueva una ciudadanía responsable con su entorno, la comprensión de la naturaleza como un recurso capital natural, pero con la salvedad que su aprovechamiento mantenga la calidad de vida de las comunidades y al mismo tiempo pueda prever la supervivencia más allá de lo económico, la supervivencia de todas las formas de vida, dándole un valor propio a la naturaleza. También se pretende que los estudiantes puedan comprender los fenómenos, biológicos, químicos y sociales que encierran los entornos de su localidad y al hacer el recorrido por los diferentes escenarios puedan desarrollar un sentido de pertenecía por el lugar donde habitan y vivificar los valores de la educación ambiental. 
Bio-grafía. Escritos sobre la Biología y su Enseñanza. ISSN 2027-1034

Número Extraordinario. p.p. 33-39

Memorias del Primer encuentro ambiental Universidad, ambiente y sustentabilidad: experiencias y prácticas.

\section{BIBLIOGRAFÍA}

- Díaz de Rada, Á. (2014). Etnografías de la educación y conceptos de educación. España: UNAD

- Foladori, G. (2002). Avances y límites de la sustentabilidad social. Revista Economía, Sociedad y Territorio, 3(12). 621-637

- Gudynas, E. (2009). Desarrollo sostenible: posturas contemporáneas y desafíos en la construcción del espacio urbano. Vivienda Popular, (18), 12-19.

- Leff, E. (2002). Saber ambiental: sustentabilidad, racionalidad, complejidad, poder. México: Siglo XXI.

- Muchavisoy, J. N. J. (1997). Los saberes indígenas son patrimonio de la humanidad. Revista Nómadas (Col), (7), 64-72.

- Naredo, J. M. (2004). Sobre el origen, el uso y el contenido del término sostenible. Cuadernos de investigación urbanística, (41), 718.

- Sauvé, L. (1999). La educación ambiental entre la modernidad y la posmodernidad: en busca de un marco educativo de referencia integrador. Tópicos, 1, 7-27.

- Sauvé, L. (2004). Una cartografía de corrientes de Educación Ambiental. Cátedra de investigación de Canadá en Educación Ambiental.

- Sauvé, L. (2010). Educación científica y educación ambiental: un cruce fecundo. Enseñanza de las Ciencias, 28(1), 05-18. 